\title{
Social Media and the Surgeon
}

\author{
David A. Margolin, $\mathrm{MD}^{1,2}$ \\ ${ }^{1}$ Department of Colon and Rectal Surgery, Ochsner Clinic Foundation, \\ New Orleans, Louisiana \\ 2 Ochsner Clinical School, University of Queensland, Brisbane, \\ Australia
}

\begin{abstract}
Address for correspondence David A. Margolin, MD, Department of Colon and Rectal Surgery, Ochsner Clinic Foundation, 1514 Jefferson Hwy., New Orleans, LA 70121 (e-mail: damargolin@ochsner.org).
\end{abstract}

Clin Colon Rectal Surg 2013;26:36-38.
Abstract
Keywords
- social media
- Facebook
- YouTube
- Linkedln

As the Internet has matured, social media has developed and become a part of our everyday life. Whether it is Facebook, YouTube, or LinkedIn, we now communicate with each other and the world in a very different manner. As physicians, and specifically colon and rectal surgeons, it is important that we understand this new technology, learn its limitations, and utilize it to foster growth of our practice, trade, and potentially result in better patient care.
Objectives: At completion of this article, the reader should have an understanding of social media including its limitations and potential to foster growth of a practice, and improve the specialty and patient care.

In case you missed it, in 2004 we entered the Web 2.0 age. In the Web 1.0 era, there were relatively few content creators and the vast majority of users were simply consumers of that content. Web1.0 involved essentially one-way communication in which users passively read the information presented. However, with technologic advances that provided ease of use, Web 2.0 was born. Almost overnight, two-way communication became a reality, and content creation became available to anyone. These technologic advances led to bidirectional communication where users could not only comment on content, but also edit and develop their own. (For an outstanding review, see http://www2.research.att.com/ bala/papers/web1v2.pdf). It seemed everyone had an equal voice, whether good or bad, truthful or not. As time went on, these websites incorporated a strong social component, and encouraged user-generated content in the form of text, video, photo postings, and blogs, all of which can occur instantaneously. Out of this social media was born, and it is not going away. In 2012, Facebook (Facebook, Inc.) surpassed 900 million users and had an initial public offering (IPO) that raised over 16 billion dollars. ${ }^{1}$ Although not without problems, this represented the third largest IPO in U.S. history to date. Twitter has over 600 million registered users, and results in over 300 million "Tweets" each day. ${ }^{2}$ LinkedIn, a social media site geared toward professionals, has over 77 million users. ${ }^{3}$ Doximity, a physician-only social network started in 2011 where physicians can use their real name, contact others, and verify credentials has over 50,000 active physicians and is now used by $9 \%$ of all doctors in the United States. ${ }^{4}$ On YouTube, there are 48 hours of video uploaded every minute-this equals nearly 8 years of content uploaded every day. ${ }^{5}$ For many of the "holdouts" on the social media stage, the numbers left behind seem to be rapidly waning.

Surgeons are no different than the general population in adopting new technologies such as social media for their personal use. An American College of Surgeons survey showed that $55 \%$ of respondents used Facebook, $48 \%$ used LinkedIn, and $82 \%$ viewed videos on YouTube for their personal use. ${ }^{6}$ However, the potential exists for more than finding old friends and that funny cat on YouTube. Social media has already played a role in grass roots political movements. For critics of this new technology who dismiss platforms like Facebook and Twitter as vapid troughs of celebrity gossip and self-aggrandizement, the toppling of regimes in Tunisia and Egypt suggested that these tools were as effective for organizing protests and revolutions. Even traditional conservative venues like the Middle East have seen an explosion of social media use. Riyadh is now the most active Twitter city in the Middle East, accounting for 2.9 million users, and reporting an over 93\% increase in growth in 6 months since the incorporation of Arabic to the site. If this same technology can do all this, it certainly can bring about changes in medicine. Currently, plastic surgeons are one group that are taking advantage of this technology. Both the American Society of Plastic Surgery (ASPS) and the American Society
Issue Theme Technology and Health Information in Colorectal Surgery; Guest Editor, Scott R. Steele, MD.
Copyright (c) 2013 by Thieme Medical Publishers, Inc., 333 Seventh Avenue, New York, NY 10001, USA. Tel: +1(212) 584-4662.
DOI http://dx.doi.org/ 10.1055/s-0033-1333646. ISSN 1531-0043. 
for Aesthetic Plastic Surgery have incorporated Facebook, Twitter, and YouTube into the national meetings and websites. ${ }^{7}$ The American Society of Colon and Rectal Surgeons (ASCRS) has also embraced social media with some initial success. Currently, there is an ASCRS Facebook page that has 1,000 friends and 361,000 unique people who are friends of people who like the ASCRS page. In conjunction with the ASCRS (American Society of Colon and Rectal Surgeons) home page and the Diseases of the Colon and Rectum (DC\&R), we are attempting to leverage these three websites to communicate with patients and providers. Furthermore, we are exploring a health care blog that will be available across the all the platforms in the near future. Yet, these are simply the beginnings, and we are currently in the infancy of their use.

The educational opportunities for social media are endless, as clinicians in remote settings now can have access to tertiary care centers and expert opinions via telemedicine and telementoring. Skype ${ }^{\mathrm{TM}}$, the free Internet-based video conference service, is currently being used to teach laparoscopic surgery in Botswana and expose medical students to international health concerns. $^{8}$ YouTube videos demonstrate multiple surgical techniques, all with the click of a mouse. Residents, fellows, and fully trained surgeons alike have reported on regular use for both educational and "brush-up" purposes. Health care practitioners are not the only ones connecting via social media. Health care organizations have recognized the importance of social media with the goal of improving outcomes, reducing costs, and improving coordination of care. In 2011, U.S. hospitals had 1,068 Facebook pages, 8,154 Twitter accounts, 566 LinkedIn accounts, 575 YouTube Channels, and 149 Blogs. ${ }^{9}$ Hospitals have long recognized that patients will turn to the Internet and social media sites to research their conditions, doctors, and hospitals. Pioneers like WebMD along with multiple others have demonstrated that a well-done Internet interaction will improve both communication and the patient's overall experience. Although this is certainly important, it will soon be tied to financial incentives. In the near future, the patient's clinical experience and perceptions of their healthcare provider and care will be tied directly to Medicare reimbursement from HCAHPS (Hospital Consumer Assessment of Health Providers and Systems). This government survey contains 18 patient perspectives on care and patient rating items that encompass eight key topics: communication with doctors, communication with nurses, responsiveness of hospital staff, pain management, communication about medicines, discharge information, cleanliness of the hospital environment, and quietness of the hospital environment. Other examples of hospitals using social media to improve patient experience are as follows: The Cleveland Clinic monitors Facebook and Twitter and uses these to address patient complaints in a timely fashion; Seattle Children's Hospital shared it condolences and apologies for an error that the led to a child's death and publicized the steps taken to prevent future errors on their Facebook page; and the Ochsner Clinic in New Orleans contacts patients via Smartphone apps with the up-to-date wait times at the various emergency rooms. ${ }^{10}$

While larger systems are out in front in utilizing a combination of social media and economies of scale, smaller practices are finding incremental gains in patient communication much more difficult. Although these small groups may benefit from blogging, online postings, or videos about diseases and treatment options, there is a significant amount of effort necessary to stay current. Large institutions have the work force to answer individual questions and rapidly update their online presence,whereas smaller practices may have difficulty in keeping up with bidirectional communication inherent in social media. Despite these difficulties, the reality remains: If you ignore your blog or social media site, or lack one altogether, you may be perceived out of touch or disinterested.

Despite the widespread public acceptance of social media, the medical community, in general, and surgeons in particular, have embraced this technology with trepidation. This is not without valid reasons. As described above, the potential impact for improved communication exists. However, it is not without vulnerability. As stated by Gerysen in 2010, medical professionals can find it difficult to apply the principles of professionalism to online communication. They need to consider the impact of their online content on the public and ensure that postings do not disregard patient privacy or create unprofessional content online that can reflect poorly on the entire profession. ${ }^{11}$ This last point is especially germane to colon and rectal surgeons due to the nature of our practice.

Professionalism is the basis of a physician's contract with society. As defined by Lesser et al, it involves compassionate, respectful, collaborative care of all patients. Furthermore, it mandates integrity, accountability, and the continued pursuit of excellence. ${ }^{12}$ Although these standards are well known and well accepted in clinical practice, the lines can be blurred in the anonymity of the Internet. Individuals surfing from home can repost or re-Tweet appropriate information, taken completely out of context, even without the awareness of the initial poster. For example, does having a beer at the family barbeque represent an alcohol problem? This may depend in part the caption posted with a picture. Lost are the intonation and emotion of verbal contact, which can lead to misconstruing a sentence. This is not restricted to medicine, as the judicial ethics advisory committee in the state of Florida has prohibited judges from accepting "friend" requests from lawyers who appear before them. ${ }^{13}$ A review of resident and medical school Facebook pages showed alcohol consumption in $10 \%$ of posts and implied overindulgence in $50 \%$. Additionally, $30 \%$ had overt sexual content and potential patient privacy violations. ${ }^{14,15}$ With that in mind, the AMA Council of Ethical and Judicial Affairs has published a policy on Professionalism in the Use of Social Media. ${ }^{16}$ These recommendations have been echoed by the American College of Surgeons. ${ }^{6}$ Although these recommendations may seem self-evident to some and draconian and out of touch to others, they do offer a framework to help physicians navigate the Internet and social media world while maintaining their professionalism. The number one priority is obvious-maintain patient privacy and confidentiality. In that vein, it is important to understand the limitations and use of the Internet platforms privacy settings. For example, Twitter explicitly states "What you say on Twitter may be viewed 
all around the world instantly." Facebook allows users to adjust who may have access to posts and images, but reposting (which would allow others to view content) can occur. In general, it is always better to err on the conservative side, and either hold back a questionable post or run it by a colleague. Similar advice is important for reposting.

Many institutions have also developed policies for their employees and the workplace. For example, the Ochsner Medical System has blocked social media access from institutional computers. Responsible use of social media by employed physicians is also discussed in written policies. It is important to know about any such policies at your institution. Ignorance is rarely a valid excuse. Distinctions are made between professional (practice or marketing sites) and personnel sites. However, as stated previously, material on the Net cannot always be compartmentalized.

In summary, social networking is nothing new. It has gone on for generations: from your grandparents communicating via a handwritten letter to you, your parents communicating via telephone to you, and your children now texting you, or perhaps teaching you how to text. Communication and relationship building has always been a part of the human condition. With each technologic advance, information can be disseminated faster, easier, and sometimes even better. To better inform and care for patients it is important that we embrace these advances.

\section{References}

1 Goldman D. Facebook tops 900 million users. Available at: http:// money.cnn.com/2012/04/23/technology/facebook-q1/index.htm. Accessed June 12, 2012
2 Twopcharts. Available at: http://twopcharts.com/twitter500million.php. Accessed June 15, 2012

3 LinkedIn. Available at: http://www.linkedin.com/answers/usinglinkedIn/ULI/700615-16801902. Accessed June 15, 2012

4 FierceHealthIT. Available at: http://www.fiercehealthit.com/ press-releases/50000-physicians-now-doximity-medical-network\#ixzz1zyc1bcbb. Accessed June 18, 2012

5 You Tube. Available at: http://www.youtube.com/t/faq. Accessed June 26, 2012

6 Yamount SZ, Lind DS, Monson RA, Glick PL. Using social media to enhance surgeon and patient communication and education. Bulletin of the ACS 2011;96:8-15

7 Camp SM, Mills DC II. The marriage of plastic surgery and social media: a relationship to last a lifetime. Aesthet Surg J 2012;32 (3):349-351

8 Leow JJ, Pozo ME, Groen RS, Kushner AL. Social media in lowresource settings: a role for Twitter and Facebook in global surgery? Surgery 2012;151(6):767-769

9 Bennett E. Found in cache. Social media resources for health care professionals. Available at: http://ebennett.org/hsnl/. Accessed June 30, 2012

10 Thielst CB. Social media: ubiquitous community and patient engagement. Front Health Serv Manage 2011;28(2):3-14

11 Greysen SR, Kind T, Chretien KC. Online professionalism and the mirror of social media. J Gen Intern Med 2010;25(11):1227-1229

12 Lesse CS, Lucey CR, Egner B, et al. A behavioral and systems view of professionalism. JAMA 2011;304:2732-2737

13 Available at: http://www.jud6.org/legalcommunity/legalpractice/ opinions/jeacopinions/2009/2009-20.html. Accessed June 18, 2012

14 Thompson LA, Dawson K, Ferdig R, et al. The intersection of online social networking with medical professionalism. J Gen Intern Med 2008;23(7):954-957

15 Chretien KC, Greysen SR, Chretien JP, Kind T. Online posting of unprofessional content by medical students. JAMA 2009;302 (12):1309-1315

16 AMA Council on Ethical and Judicial Affairs. Professionalism in the Use of Social Media. J Clin Ethics 2011;22:97-104 